\title{
Dual exon skipping in myostatin and dystrophin for Duchenne muscular dystrophy
}

\author{
Dwi U Kemaladewi ${ }^{1,2}$, Willem MH Hoogaars', Sandra H van Heiningen ${ }^{1}$, Samuel Terlouw ${ }^{1}$, David JJ de Gorter ${ }^{2,3}$, \\ Johan T den Dunnen', Gert Jan B van Ommen', Annemieke Aartsma-Rus ${ }^{1}$, Peter ten Dijke ${ }^{2}$ and \\ Peter $\mathrm{AC}{ }^{\prime} \mathrm{t} \mathrm{Hoen}^{1 *}$
}

\begin{abstract}
Background: Myostatin is a potent muscle growth inhibitor that belongs to the Transforming Growth Factor- $\beta$ (TGF- $\beta$ ) family. Mutations leading to non functional myostatin have been associated with hypermuscularity in several organisms. By contrast, Duchenne muscular dystrophy (DMD) is characterized by a loss of muscle fibers and impaired regeneration. In this study, we aim to knockdown myostatin by means of exon skipping, a technique which has been successfully applied to reframe the genetic defect of dystrophin gene in DMD patients.

Methods: We targeted myostatin exon 2 using antisense oligonucleotides (AON) in healthy and DMD-derived myotubes cultures. We assessed the exon skipping level, transcriptional expression of myostatin and its target genes, and combined myostatin and several dystrophin AONs. These AONs were also applied in the mdx mice models via intramuscular injections.

Results: Myostatin AON induced exon 2 skipping in cell cultures and to a lower extent in the mdx mice. It was accompanied by decrease in myostatin mRNA and enhanced MYOG and MYF5 expression. Furthermore, combination of myostatin and dystrophin AONs induced simultaneous skipping of both genes.

Conclusions: We conclude that two AONs can be used to target two different genes, MSTN and DMD, in a straightforward manner. Targeting multiple ligands of TGF-beta family will be more promising as adjuvant therapies for DMD.
\end{abstract}

\section{Background}

Duchenne muscular dystrophy (DMD) is an X-linked recessive neuromuscular disorder, which is caused by dystrophin deficiency in muscle fibers. DMD fibers are more sensitive to muscle damage, leading to degeneration and replacement of muscle fibers by fat and connective tissue (fibrosis). Monaco et al found that frame shift mutations in the $D M D$ gene will lead to a truncated and non-functional form of dystrophin [1], which become the primary cause of the disease. However, mutations which maintain the $D M D$ open reading frame result in shorter dystrophin proteins that retain the essential actin binding-, cysteine rich- and carboxy terminal domains, and thus are partly functional [1].

\footnotetext{
* Correspondence: p.a.c._t_hoen@lumc.nl

${ }^{1}$ Center for Human and Clinical Genetics, Leiden University Medical Center,

Postzone S4-P, PO Box 9600, Leiden, 2300RC, the Netherlands

Full list of author information is available at the end of the article
}

Patients with such mutations develop the less severe Becker muscular dystrophy. This reading frame rule holds true for $\sim 91 \%$ of DMD cases [2] and has inspired the development of the exon skipping strategy, which employs antisense oligonucleotides (AONs). These small synthetic RNA molecules are complimentary to exonic or splice site sequences, thereby upon hybridization are able to modulate exon inclusion by the splicing machinery (recently reviewed in [3-5]).

Comprehensive studies done by our group and others have provided the proof of principle of the therapeutic feasibility of the AON to reframe dystrophin transcripts and restore dystrophin synthesis, both in vitro [6-8] and in vivo using the $m d x$ and hDMD mice [9-11]. Subsequent clinical trials have shown that two different AON chemistries, either 2'-O-methyl phosphorothioate (2'OMePS) [12] or phosphorodiamidate morpholino oligomer (PMO) [13] targeting DMD exon 51 can restore

\section{Biomed Central}


local dystrophin synthesis in DMD patients with no to minimum side effect.

However, other major facets of DMD pathology which include severe muscle wasting, fibrosis and flawed muscle regeneration may reduce the efficacy of the $D M D$ exon skipping therapy. In addition, as DMD patients suffer from muscle degeneration from their early life, myoblasts undergo extensive division in an attempt to regenerate, which eventually leads to exhaustion of the muscle regenerative potential [14-16]. Therefore, several additional therapies have been considered to overcome these problems, in which myostatin inhibition has received considerable interest.

Myostatin or Growth and Differentiation Factor-8 (GDF-8), an evolutionary conserved TGF- $\beta$ family member that is expressed predominantly in skeletal muscle, is a potent muscle growth inhibitor. Natural mutations or targeted knockdown in the MSTN genes, which lead to non-functional proteins are associated with hypermuscularity in several organisms such as mice, cattles, dog, horse, sheep and human [17-21]. Myostatin signaling requires binding to the Activin type IIB receptor (AcvRIIb) and Activin receptor-like kinase 4/5 (ALK4/5) receptor complex and subsequent phosphorylation of downstream Smad2 and Smad3 [22], which further influences myogenesis through transcriptional regulation of cell cycle and myogenic regulatory factors [23-27]. Several strategies to block myostatin such as neutralizing antibodies [28-30], overexpression of its inhibitory propeptide [31-34], or administration of soluble AcvRIIB [35] induced increases in muscle mass and force and reduced fibrosis in the $m d x$ mice [36].

A recent study by Dumonceaux et al [37] targeted the myostatin receptor AcvRIIb using shRNA and coupled it with a modified U7 small nuclear RNA to restore dystrophin in single adeno-associated vectors (AAV). This study showed that combination therapy has an added value in improving muscle physiology. However, as recently reviewed by Tang et al [38], one major limitation of AAV-based gene therapy approach is the immune response against the vector and/or transgene.

In this study we chose to use 2 'OMePS AON to target $M S T N$ exon 2 and disrupt its translational reading frame in order to knockdown its expression level. As it harbors the same chemistry modification as the PRO051 DMD AON currently in trial, we hypothesized that the administration of the two AONs as a cocktail would be achievable and may thus yield a combination treatment by simultaneously correcting the $D m d$ transcript and downregulating the Mstn transcript. In addition, as recently reviewed in [39], the 2'OMePS modification enhances the stability and increases the in vivo half-life compared to the previously studied butanol-tagged antisense [40] or siRNA-mediated RNA interference approaches targeting myostatin [41]. We evaluated its feasibility to induce exon skipping and downregulate MSTN expression in myotubes cultures and DMD mouse models. Furthermore, we combined it with several DMD AONs to look into the possibility of skipping two genes simultaneously (Figure 1).

\section{Methods}

\section{Antisense oligonucleotides}

AON with phosphorothioate backbones and 2'-O-methyl ribose modifications used in this study were synthesized and high-pressure liquid chromatography purified by Eurogentec, Belgium. The sequences are listed in Table 1.

\section{Cell culture}

Human primary myoblasts obtained from a healthy donor (KM109) [42], immortalized myoblast cell line (7304-1) generated by expressing telomerase (hTERT) and cyclindependent kinase 4 [43], and DMD patient derived myoblasts with a deletion in exon 51-55 (DL589.2) [7] were used in this study. All of the cells mentioned above were seeded on thin layer collagen (1:30, PureCol, Inamed Biomaterials, Fremont). The primary cells were grown in Nut. Mix F-10 (HAM) supplemented with GlutaMax-I, 20\% Fetal Bovine Serum (FBS) and 1\% Penicillin/Streptomycin (Gibco-BRL) at $37^{\circ} \mathrm{C}, 5 \% \mathrm{CO}_{2}$. The 7304-1 cells were cultured in Skeletal Muscle Cell Basal Medium supplemented with 15\% FBS, $5 \mu \mathrm{g}$ hEGF, $0.5 \mu \mathrm{g}$ hFGF, 25 mg Fetuin, 5 $\mathrm{mg}$ Insulin and $200 \mu \mathrm{g}$ Dexamethasone (PromoCell GmbH, Germany). 80-90\% confluent culture was induced to differentiate into myotubes in DMEM supplemented with $2 \% \mathrm{FBS}, 1 \% \mathrm{P} / \mathrm{S}, 2 \%$ Glutamax and $1 \%$ glucose (Gibco-BRL), except the 7304-1 in which 2\% of Horse Serum was added instead of FBS.

\section{AON transfections}

Myotubes were transfected with different dilutions of $\mathrm{AON}$ in $0.15 \mathrm{M} \mathrm{NaCl}$ using $2.5 \mu \mathrm{l}$ polyethylenimine (ExGen 500, MBI Fermentas) per $\mu \mathrm{g}$ of AON for 3 hours.

\section{Animals and AON injections}

All experiments were performed with 5-6 weeks old $m d x$ mice under the approval of the Animal Experimental Committee (DEC07195) of the LUMC. In the single injection experiments, the AONs were administered into the gastrocnemius muscle at the dose of $40 \mu \mathrm{g}$ per injection in $50 \mu \mathrm{l}$ physiological salt. Control DMD AON (M23D) was injected in the contralateral muscle. After 4 days, the mice $(n=2)$ were sacrificed and muscles were isolated, snap frozen and sectioned at three different positions (proximal, medial and distal relative to the tendon) for total RNA isolation.

In the consecutive injections experiments, cocktails of MSTN or control AONs with M23 DMD AON were 


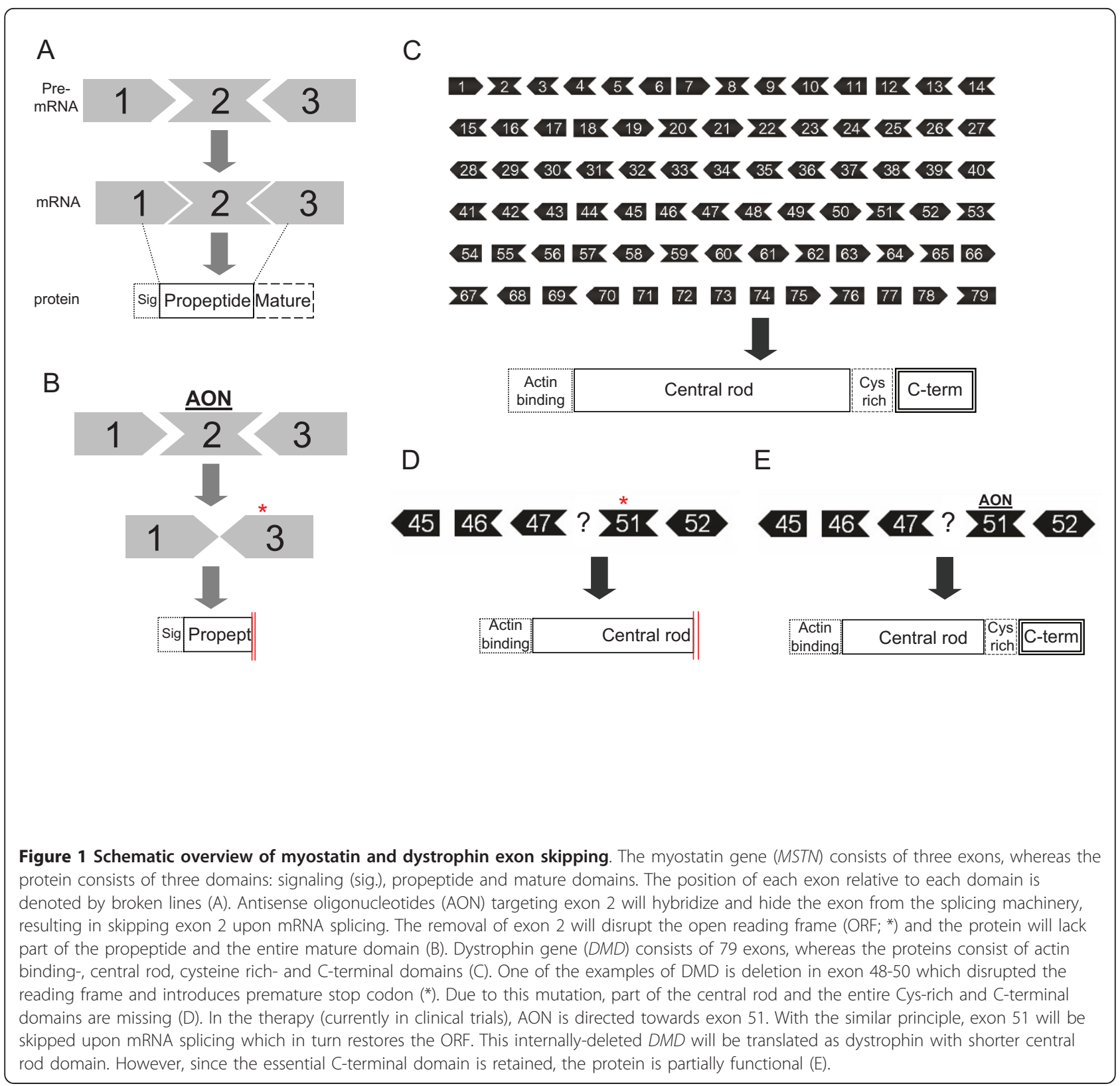

Table 1 Antisense oligonucleotides used in this study

\begin{tabular}{lll}
\hline AON & Targeting & Sequences (5'-3') $^{\prime}$ \\
\hline AON1 & Myostatin exon 2 & guuugaugagucucaggauu \\
AON2 & Myostatin exon 2 & gccaaauaccagugccu \\
AON3 & Myostatin exon 2 & agccaauuuugcaacacugu \\
h8AON3 & Human dystrophin exon 8 & guacauuaagauggacuuc \\
h44AON1 & Human dystrophin exon 44 & cgccgccauuucucaacag \\
h51AON1 & Human dystrophin exon 51 & ucaaggaagauggcauuucu \\
h54AON1 & Human dystrophin exon 54 & uacauuugucugccacugg \\
M23D (+02-18) & Mouse dystrophin exon 23 & ggccaaaccucggcuuaccu \\
\hline
\end{tabular}

injected at the dose of $40+40 \mu \mathrm{g}$ per injection into the gastrocnemius muscle. Four consecutive injections were performed with a 48 hours resting time between the second and third injection. The mice $(\mathrm{n}=6)$ were sacrificed at 6 hours, 1 and 2 days after the last injection. The muscles were isolated, snap frozen and sectioned. Pool of sections from different area of the muscles was collected for RNA isolation.

\section{RNA Isolation, RT-PCR and Quantitative PCR analysis}

Cell lysates were prepared using lysis buffer provided in the NucleoSpin RNA II kit (Macherey-Nagel, Germany) 
and RNA was isolated using the same kit according to manufacturer's instructions. Sectioned muscles were initially lysed using the same buffer and crushed with MagNA Lyser Green beads in the MagNA Lyser instrument (Roche Diagnostics, Germany) at 7000 oscillation speed for $2 \times 20$ seconds. RNA was isolated using the same procedure. The RNA quantity and integrity were measured using RNA 6000 Nanochip in the Agilent 2100 bioanalyzer (Agilent Technologies). cDNA was synthesized from $500 \mathrm{ng}$ of RNA using RevertAid H Minus M-MuLV Reverse Transcriptase (MBI Fermentas) with $40 \mathrm{ng}$ of random hexamer primer, according to the manufacturer's instructions. $10 \times$ diluted cDNA was then amplified by PCR using primers listed in Table 2. Myostatin amplifications were performed at $94^{\circ} \mathrm{C}(30 \mathrm{~s}), 56^{\circ} \mathrm{C}$ (30 s), $72^{\circ} \mathrm{C}(60 \mathrm{~s})$ for 30 cycles. Dystrophin PCRs were performed in two rounds. The first PCR was performed by 20 cycles of $94^{\circ} \mathrm{C}(40 \mathrm{~s}), 60^{\circ} \mathrm{C}(40 \mathrm{~s}), 72^{\circ} \mathrm{C}(80 \mathrm{~s}) .1 .5$ $\mu \mathrm{l}$ of these reactions were then reamplified in nested PCRs by 32 cycles of $94^{\circ} \mathrm{C}(40 \mathrm{~s}), 60^{\circ} \mathrm{C}(40 \mathrm{~s}), 72^{\circ} \mathrm{C}(60$ s). Quantitative PCRs were carried out in a 384-wells plate with $2 \mu \mathrm{l}$ of $10 \mathrm{X}$ diluted cDNA, $1 \mu \mathrm{l}$ of $1 \mathrm{pmol} / \mu \mathrm{l}$ forward primers, $1 \mu \mathrm{l}$ of $1 \mathrm{pmol} / \mu \mathrm{l}$ reverse primers and $6 \mu \mathrm{l}$ of iQ ${ }^{\mathrm{TM}}$ SYBR $^{\circledR}$ Green Supermix (Bio-Rad) in LightCycler 480 (Roche Diagnostics, Germany). Each measurement was performed in triplicates. Expressions of the genes of interest were normalized to housekeeping gene $G A P D H$ and analyzed using $\triangle \triangle \mathrm{Ct}$ method with Gene

Table 2 Primers used in this study

\begin{tabular}{|c|c|c|}
\hline Primers & Sequences & Used for \\
\hline Mstn Ex1F & GGAAACAGCTCCTAACATCAG & $\begin{array}{l}\text { Myostatin exon } 2 \text { skip } \\
\text { PCR }\end{array}$ \\
\hline Mstn Ex3R & CTGAGCAGTAATTGGCCTTATATC & \\
\hline $\begin{array}{l}\text { Mstn } \\
\text { Ex1F1 }\end{array}$ & GATGACGATTATCACGCTAC & Myostatin QPCR \\
\hline $\begin{array}{l}\text { Mstn } \\
\text { Ex2R1 }\end{array}$ & GCACAAACACTGTTGTAGGA & \\
\hline Myog Fw & GCCAGACTATCCCCTTCCTC & Myogenin QPCR \\
\hline Myog Rev & AGGGATGCCCTCTCCTCTAA & \\
\hline Myf5 Fw & CCACCTCCAACTGCTCTGAT & Myf5 QPCR \\
\hline Myf5 Rev & GCAATCCAAGCTGGATAAGG & \\
\hline Gapdh Fw & CAATGACCCCTTCATTGACC & Gapdh QPCR \\
\hline Gapdh Rev & GACAAGCTTCCCGTTCTCAG & \\
\hline DMD Ex6F & CTGGCTITGAATGCTCTCATC & DMD exon 8 skip PCR \\
\hline $\begin{array}{l}\text { DMD } \\
\text { Ex11R }\end{array}$ & GCTGTCAAATCCATCATGTACC & \\
\hline $\begin{array}{l}\text { DMD } \\
\text { Ex42F }\end{array}$ & GTGATGACTGAAGACATGCC & DMD Exon 44 skip PCR \\
\hline $\begin{array}{l}\text { DMD } \\
\text { Ex45R }\end{array}$ & TCTGTCTGACAGCTGTITGC & \\
\hline $\begin{array}{l}\text { DMD } \\
\text { Ex53F }\end{array}$ & TTCAGAATCAGTGGGATGAAG & DMD Exon 54 skip PCR \\
\hline $\begin{array}{l}\text { DMD } \\
\text { Ex56R }\end{array}$ & CGTCIITGTAACAGGACTGC & \\
\hline
\end{tabular}

Expression Analysis for iCycler $\mathrm{iQ}^{\circledR}$ Real-Time PCR Detection System software developed by Bio-Rad. The expression values of 3-4 biological experiments were averaged. For the statistical analysis, the expressions in MSTN AON-transfected samples were compared to 500 $\mathrm{nM}$ control AON transfected samples in Student's t-test. P-values $<0.05$ were considered significant.

\section{Results}

\section{Myostatin AON induces exon 2 skip in vitro}

Based on previously described guidelines [44], we designed three AONs targeting different regions in MSTN exon 2 gene and used previously designed AONs targeting $D M D$ exons as controls (Table 1). All AONs consisted of 2'-O-methyl RNA and had a phosphorothioate backbone in order to resist endonucleases and RNaseH degradation. We evaluated their efficiency using immortalized human myoblasts (7304-1) as well as primary myoblasts from a healthy individual (KM109) and a DMD patient with a deletion in exon 51-55 (DL589.2). We used differentiated myotube cultures because the expression levels of myostatin and dystrophin were found to be higher in the differentiation than in proliferation stage (data not shown).

To examine the feasibility to induce myostatin exon 2 skipping, different concentrations of each AON were transfected into the myotube cultures using the cationic polymer polyethylenimine (PEI). More than $80 \%$ of the cells showed specific nuclear uptake upon transfection with 5'-fluorescein (FAM)-labeled control AON (Figure 2A). RT-PCR performed two days post transfection (Figure $2 \mathrm{~B}$ ) and subsequent sequencing analysis (Figure 2C) showed the exclusion of exon 2 from the myostatin transcript in the myostatin AON-transfected cells, resulting in a premature stop codon formation. This internally truncated fragment was not observed in any of the non-transfected and control AON-transfected myotubes. One myostatin AON, namely AON1, gave the most consistent and highest skipping efficiency [Additional file 1]. Thus we further used the AON1 (addressed as myostatin AON from now on) and confirmed its exon skipping ability in human and to a lower extent in mouse cells models, using its perfect complementary to the human and mouse MSTN sequences (Figure 2B and not shown).

\section{AON-mediated exon skipping decreased myostatin transcript expression level and increased expression of myogenic regulatory factors}

Next, we determined the expression level of MSTN transcript upon exon skipping by quantitative real time PCR. We used primers in exon 1 and exon 2, thereby detecting only the non-skipped products. As shown in Figure 2D, the levels of full length $M S T N$ transcript 


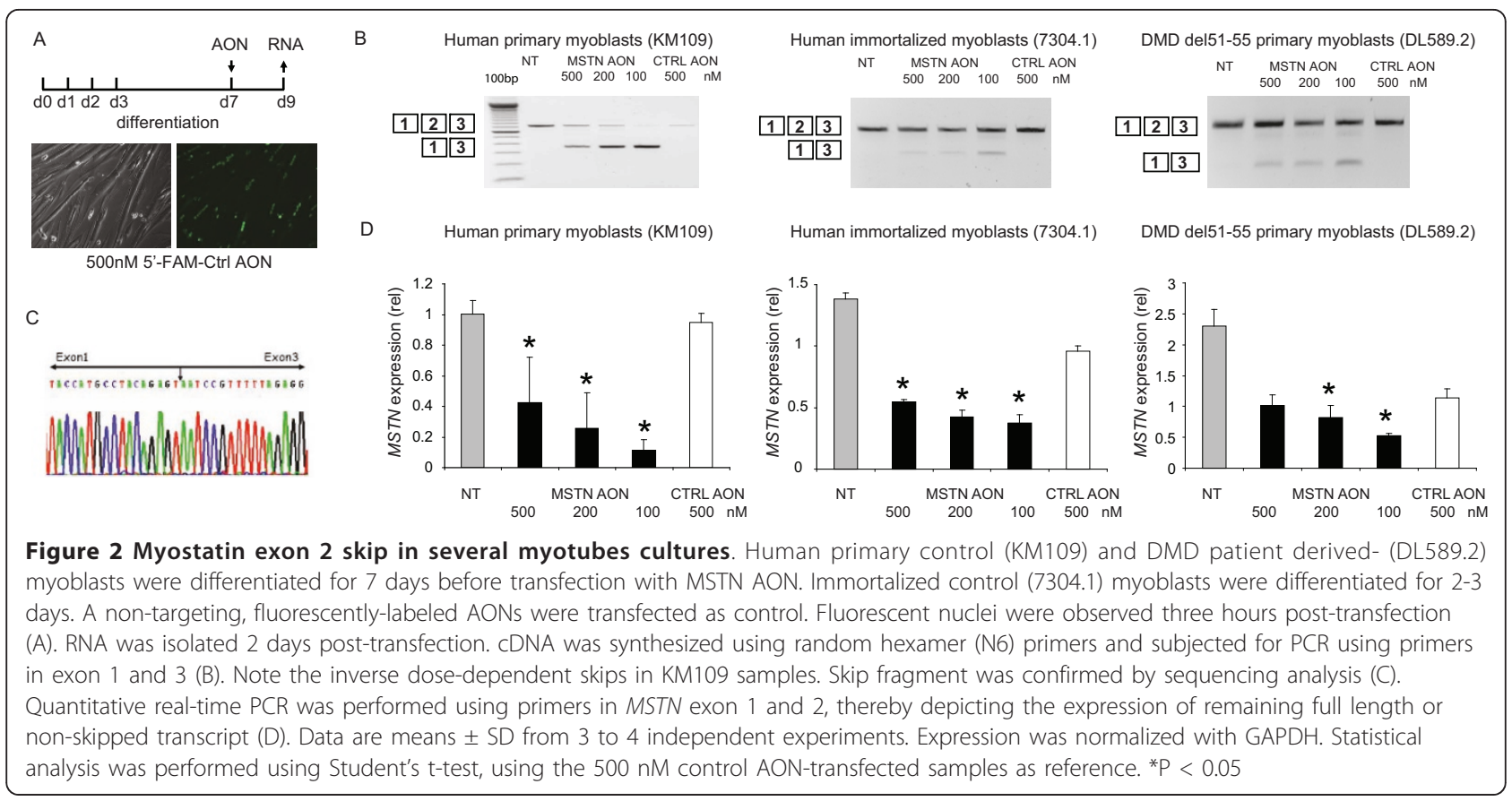

decreased significantly in the myostatin AON-transfected samples, with slight variations in the knockdown levels between different cells. Notably, these decreases were achieved in an inverse dose-dependent manner, meaning that the most pronounced knockdown was achieved with $100 \mathrm{nM}$ AON, which was the lowest concentration of myostatin AON tested. This effect was seen especially in the KM109 cells. In addition, the control AON induced less pronounced but still significant decreases of the full-length MSTN levels in some cells (7304-1 and DL589.2) (Figure 2D), which might be due to the transfection. Therefore, the expression levels in myostatin AON-transfected samples were compared with those in the control AONtransfected samples.

As outlined in Figure 1B, myostatin skipping results in premature stop codon in exon 3 and thus non-functional myostatin protein. Several studies have described that myogenic cells respond to myostatin by down-regulating the expression of key transcriptional regulators of muscle development such as Pax3, Pax7, p21, MyoD, Myf5 and Myog [23-27,45,46], explaining its inhibitory effects in differentiation. Therefore, inhibition of myostatin should lead to an increased expression of these myogenic regulators and thus can be used as a functional readout of the myostatin knockdown. Correspondingly, knockdown of myostatin in differentiated myotubes cultures resulted in a consistent upregulation of MYF5 and MYOG expression (Figure 3A and 3B). The fold increase varied between 3-12 fold and dependent on the myoblast cultures used, which may reflect the different myogenic differentiation potential of the different myoblast cultures.

\section{Dual exon skipping in MSTN and DMD in control and DMD patient derived myotubes}

Our ultimate goal was to use AONs to simultaneously reframe the mutation in the $D M D$ gene and to downregulate MSTN expression in order to correct the primary genetic defect as well as to enhance muscle regeneration. Therefore, we combined the myostatin AON with several DMD AONs used in the previous studies $[6,7,47]$. We specifically applied DMD AONs covering the hotspot mutated regions in $D M D$ gene, namely h8AON3, h44AON1, h51AON1 and h54AON1 (Table 1 ) in control myotubes cultures (primary (KM109) or immortalized myoblasts (7304-1)). Myotubes were transfected with either myostatin or DMD AONs or a mix of both. As shown in Figure 4, MSTN exon skip was observed in all myostatin AON-transfected samples, regardless of the presence of DMD AON. Vice versa, all DMD AON-transfected myotubes showed the exon-specific dystrophin skips described before $[6,7,47]$, regardless of the presence of MSTN AON. To investigate the possibility that the two AONs hybridized to each other rather than to their intended target, we varied the transfection conditions by mixing the AON before complexing with PEI, or preparing the AON-PEI complexes separately. However, no difference in their efficiency to induce skipping was found. We observed skipping with the total AON concentration of $200 \mathrm{nM}$ (Figure 4) as well as $100 \mathrm{nM}$ (not shown). These results demonstrated 


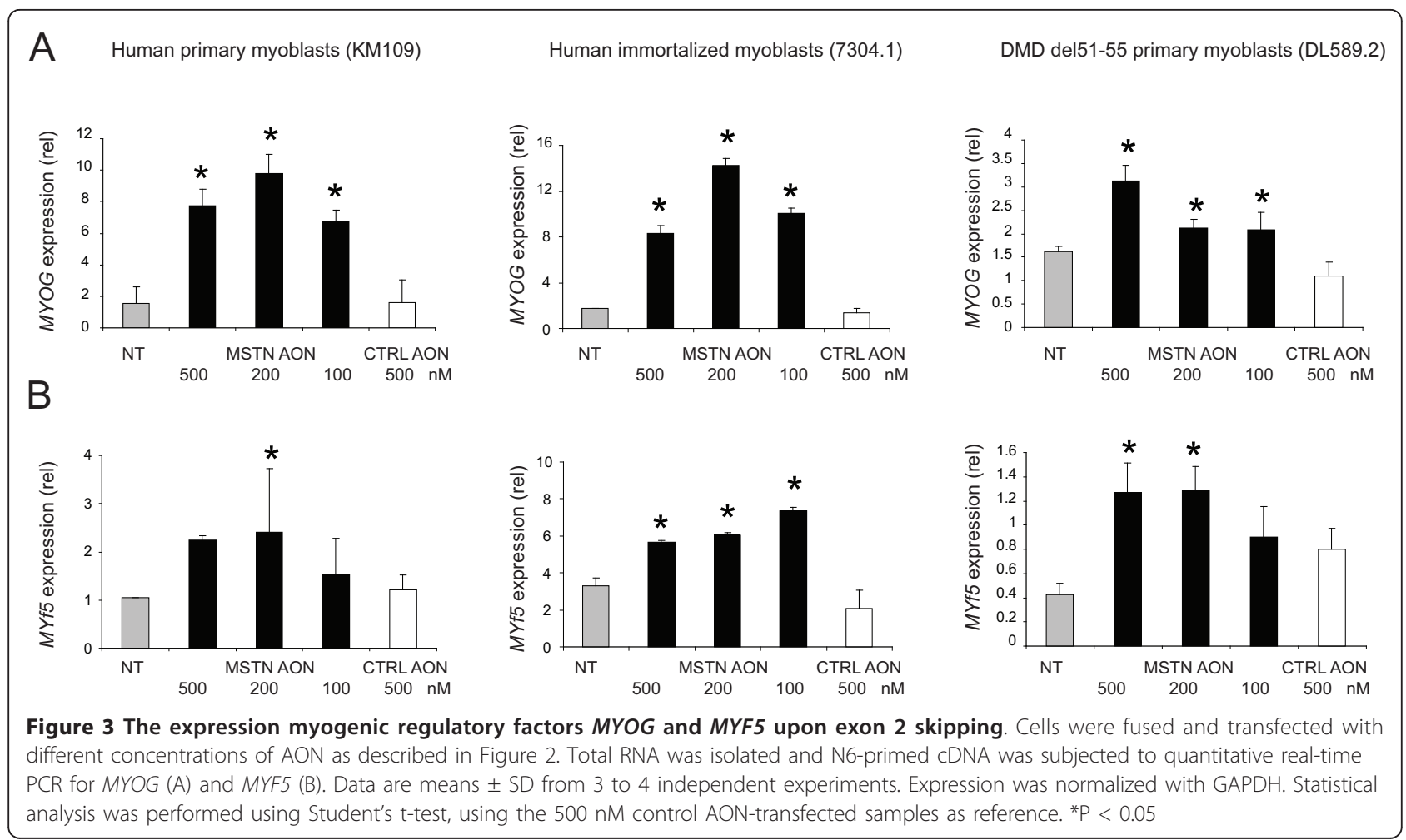

the feasibility of simultaneous antisense-mediated skipping of exons of two different genes.

To further assess its therapeutic potential, we performed dual exon skipping in the DL589.2 cells, which were derived from a DMD patient with an exon 51-55 deletion. Our previous study has shown that the reading frame can be corrected by an exon 50 skip upon transfection with h50AON1 [7]. As shown in Figure 5, combining this AON with the myostatin AON showed clear targeted skipping of both DMD and MSTN.

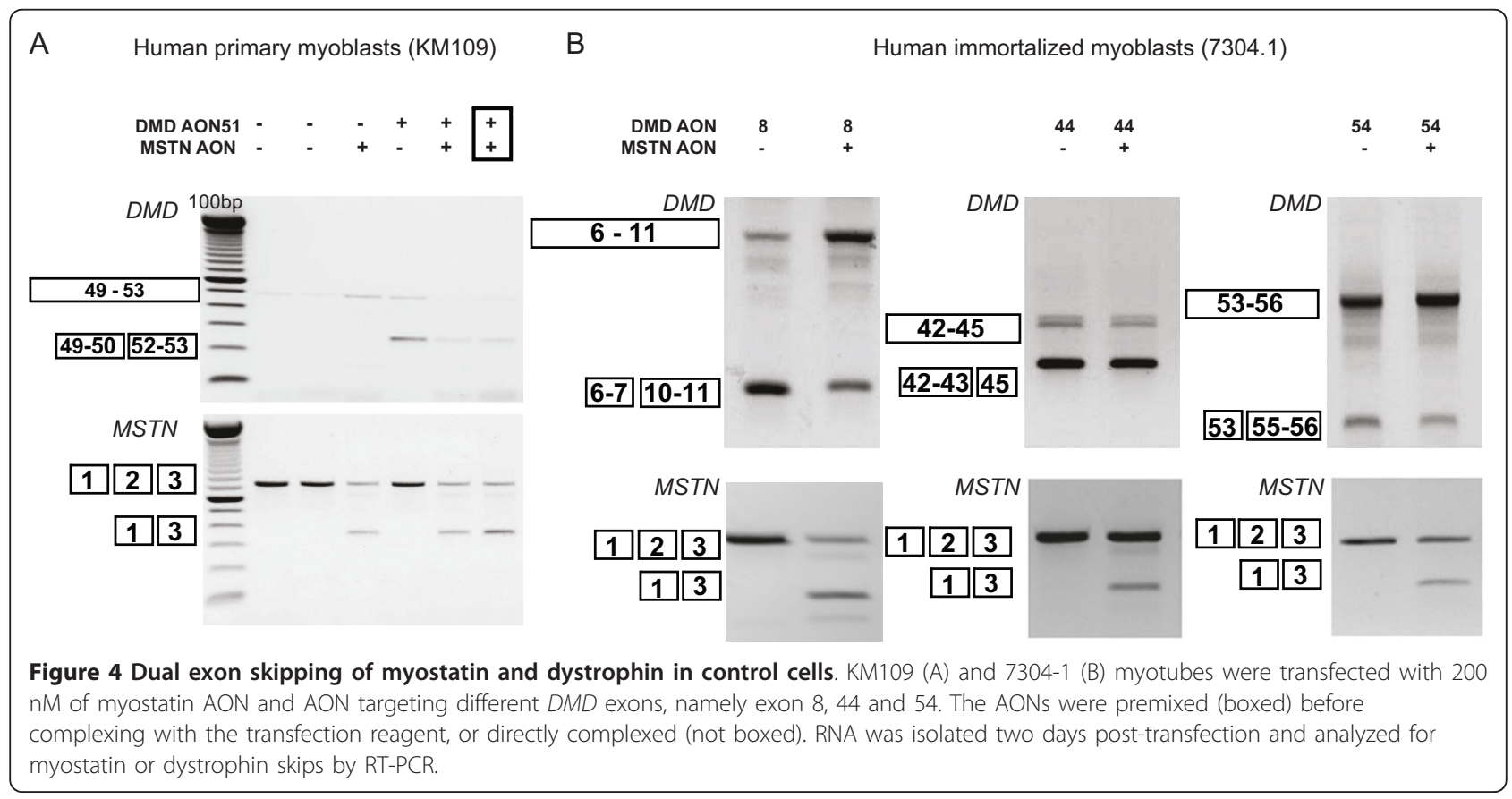




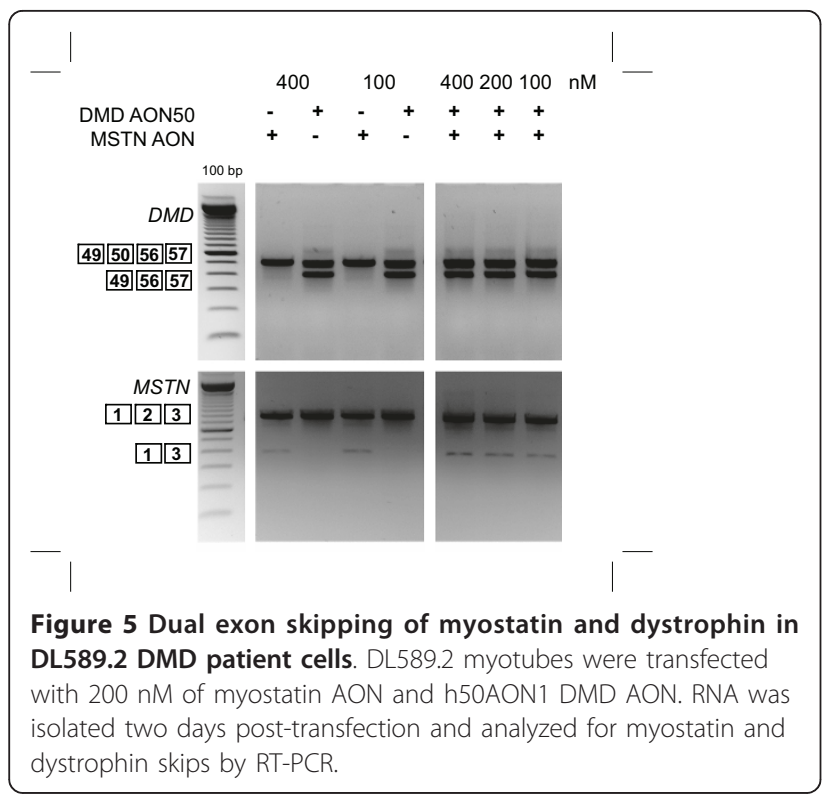

\section{Myostatin exon skipping in vivo}

We subsequently examined the ability of myostatin AON to induce exon skipping in the $m d x$ mouse model. Myostatin AON was injected at a dose of $40 \mu \mathrm{g} /$ injection into the gastrocnemius muscle of the $m d x$ mice. DMD AON targeting exon 23 (M23D, previously denoted as $\mathrm{M} 23 \mathrm{D}(+02-18)$ [9]) was injected into the contralateral muscle. This AON served as a positive control and was shown by many different groups including ours $[9,11]$ to induce efficient and robust exon skipping. The mice were sacrificed at four days after injection. We classified different sections of the muscles as the proximal (P), medial (M) and distal (D) relative to the tendon and observed heterogenous patterns of Mstn exon 2 skips (Figure 6A). The skipping levels in the proximal and medial parts of the muscles were higher than in the distal, while Dmd skips appeared to be heterogenous throughout the muscles.

Our previous study in dystrophin exon skipping had indicated that higher skipping efficiencies could be obtained by multiple injections of the AON. In order to increase the efficiency of the myostatin $\mathrm{AON}$ and to answer whether dual skipping can be achieved in vivo, we injected cocktails of M23D DMD AON with myostatin or control AONs once a day for four times, with a 48 hours resting time between the second and third injections. RT-PCR analysis was performed from RNA isolated from proximal, medial and distal parts of the muscle (Figure 6B). 6 hours after the last injection, we already observed weak myostatin skip in one of the two injected muscles. At the later time points, the skipping levels modestly increased, suggesting a trend of accumulations of skipping over time. Conversely, the Dmd skips

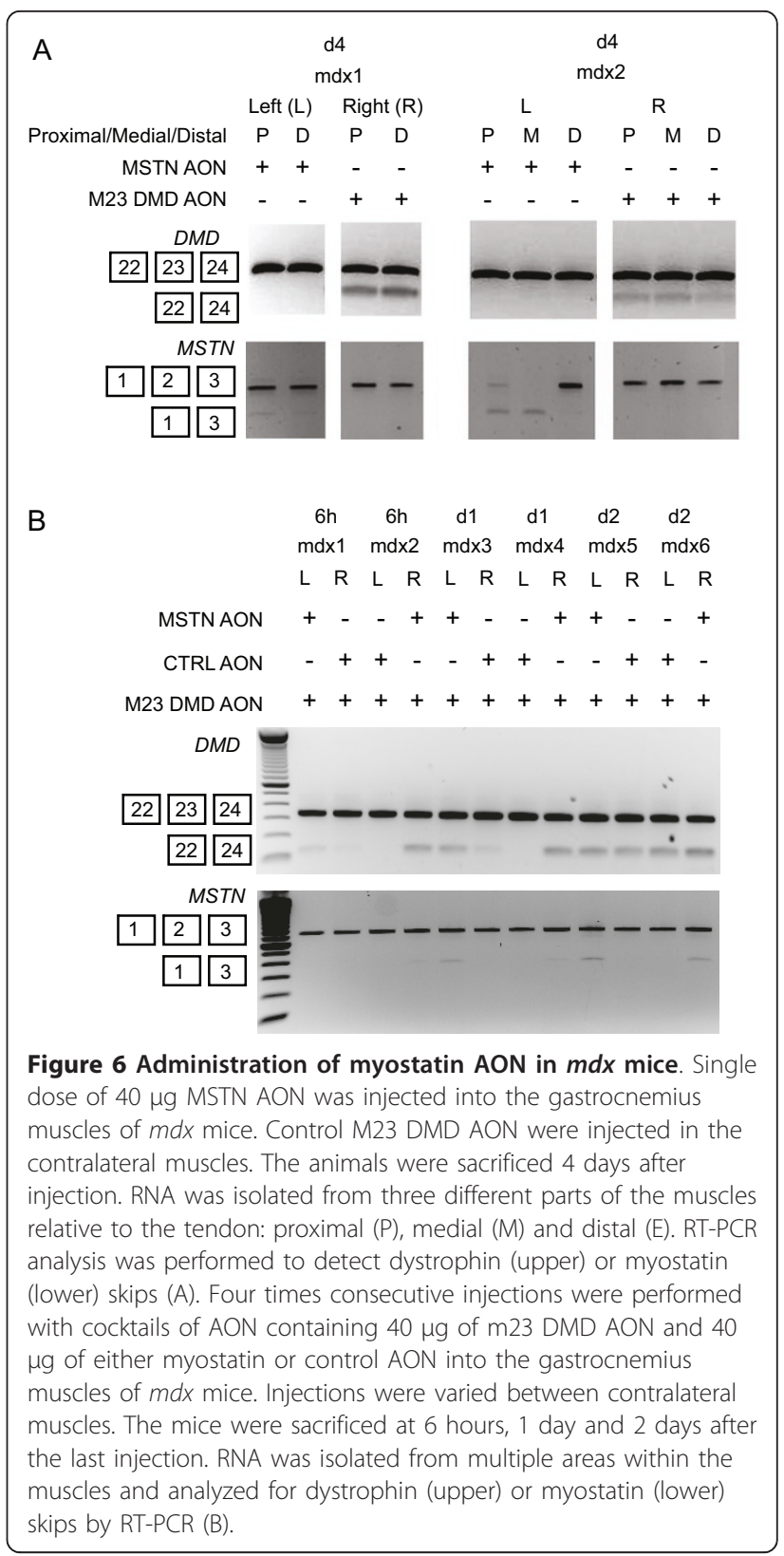

showed relatively more stable and more importantly higher skipping levels.

\section{Discussion}

DMD patients suffer from progressive muscle wasting due to the absence of functional dystrophin protein. The AON-mediated exon skipping therapy has been shown to successfully reframe the mutated $D M D$ gene and restore local dystrophin synthesis in DMD patients $[12,13]$. This approach is currently viewed as one of the most promising therapeutic approaches for DMD. However, it targets dystrophin transcripts, which are produced only in muscle and not in adipose and fibrotic 
tissues, thus does not specifically aim to enhance muscle regeneration or reduce fibrosis levels. To address both the underlying genetic defect and the loss of muscle, we here explored the possibility of using AONs to inhibit myostatin expression and AONs to reframe dystrophin transcripts simultaneously.

Our results show that the second exon of the MSTN gene can be skipped in multiple myotube cultures, either derived from healthy individuals, DMD patient or mouse. The removal of exon 2 disrupts the open reading frame and introduces premature stop codon. We observed downregulation of myostatin transcript levels up to 50$80 \%$, depending on the type of cells tested. One can expect the truncated transcripts to be degraded via nonsense mediated decay, thus not being translated into proteins. Nonetheless, we observed a clear skip product in the RT-PCR analysis, suggesting that the transcript might be fairly stable. However, the premature stop codon introduced will result in truncated myostatin protein that lacks $\sim 25 \%$ of the propeptide and the entire mature domains, which will abrogate its downstream signaling.

The effects of interventions with myostatin expression in muscle differentiation were assessed by increased expressions of MYF5 and MYOG. Although the expression levels of these genes were increased in all samples transfected with MSTN AON, there was no clear correlation between the fold decrease of MSTN and the fold increase of MYF5 and MYOG. One explanation for this observation could be that a threshold effect of myostatin knockdown on the expression of these genes is already attained when the MSTN transcript is slightly downregulated. However, the fact that we observed the upregulation of these genes in three to four independent experiments using different myoblasts suggests that this effect of myostatin downregulation using MSTN AON is valid and reproducible.

Finally, the mix of myostatin and dystrophin AONs showed that skipping two genes is feasible without interfering each other. The experimental set up was varied by mixing the AONs before complexing with the transfection reagent, or by preparing complex of $\mathrm{AON}$ and transfection reagent separately before mixing with each other to rule out the possibility that two AONs hybridize to each other. There seems to be no difference in the skipping efficiency, regardless if both AON were pre-mixed or not. However, we recommend to check the hybridization-likelihood by verifying the sequences of both AONs using freely available software tools such as RNAstructure [48].

One less encouraging finding was considerably low Mstn skipping level in vivo compared to the cultured cells. The M23D dystrophin AON, which was injected as a control in the contralateral muscle resulted in higher dystrophin skipping efficiency, confirming that the AON was injected properly. Repeated injections only showed modest improvements in the exon skipping level of myostatin. We also observed heterogenous skipping patterns throughout the muscles which seem to be specific for Mstn and not Dmd. We offer two reasons to explain the low myostatin skipping in vivo. First, we noted that the myostatin exon skipping efficiency in mouse cells was lower than in human cells in vitro. Thus, there is a possibility of species-dependent differences in the efficiency of our myostatin AON, although the AON was designed for both human and mouse. Another explanation might be that myostatin is also expressed in muscle satellite cells and fibroblasts. In vitro, we indeed saw higher $M S T N$ expression in primary cultures containing mix populations of fibroblasts and myoblasts than in immortalized myoblasts. We previously demonstrated that the leaky muscle membrane facilitates the AON to enter the muscle fibers, where dystrophin is predominantly expressed, thus explaining the high efficiency of dystrophin AON. The delivery of the AON to fibrotic area and satellite cells, where myostatin is also expressed will presumably be more difficult. Furthermore, a recent study by Kang et al [49] which also targeted myostatin exon 2 showed efficient exon skipping in vivo using octa guanidine morpholino oligomers. The chosen chemistry seems to be the key to facilitate the delivery and thereby inducing prominent exon skipping in vivo. Finally, several studies have shown that members of the TGF-beta family other than myostatin are responsible in inhibiting muscle differentiation $[35,50,51]$. Therefore, as a future prospective, targeting multiple ligands seems to be a more promising strategy, especially when combined with dystrophin restoration.

\section{Conclusions}

In conclusion, our results provide a rationale for the use of two AONs targeting two different genes and further extend the versatility of exon skipping-based therapy. The efficiency and delivery techniques remain to be improved, especially for further in vivo studies. While the correction of genetic defect is essential, combination with other adjuvant therapies which do not rely solely on myostatin inhibition, but also other TGF-beta family members regulating muscle differentiations might be more beneficial for DMD therapies.

\section{Additional material}

Additional file 1: Human primary control (KM109) myoblasts were differentiated for 7 days before transfection with 3 different MSTN AONs at $\mathbf{5 0 0}$ and $\mathbf{1 0 0} \mathbf{n M}$ concentrations. All AONs were designed to target exon 2 of the myostatin gene. The sequences are listed in table 1. RNA was isolated 2 days post-transfection. cDNA was synthesized using 
random hexamer (N6) primers and subjected for PCR using primers in exon 1 and 3 .

\section{Acknowledgements}

We would like to thank Dr. Michael Antoniou (King's College London) and Dr. Jennifer E. Morgan (Dubowitz Neuromuscular Centre, University College of London) for providing myoblasts used in this study. This work was funded by the Dutch Duchenne Parent Projects (to PACtH) and Centre for Biomedical Genetics (to PtD and GJvO).

\section{Author details}

${ }^{1}$ Center for Human and Clinical Genetics, Leiden University Medical Center, Postzone S4-P, PO Box 9600, Leiden, 2300RC, the Netherlands. 'Department of Molecular and Cell Biology, Leiden University Medical Center, Postzone S1-P, PO Box 9600, Leiden, 2300RC, the Netherlands. ${ }^{3}$ Institute for Molecular Cell Biology, University of Münster, Schlossplatz 5, Münster, D-48149, Germany.

\section{Authors' contributions}

DUK performed experiments and wrote the manuscript, WMH participated in study design and performed experiments, SHvH and ST performed experiments, DjdG, JTdD, GJBvO, AAR and PtD participated in study design, PAtH conceived and coordinated the study. All authors read and approved the final manuscript.

\section{Competing interests}

The authors declare that they have no competing interests.

Received: 28 May 2010 Accepted: 20 April 2011 Published: 20 April 2011

\section{References}

1. Monaco AP, Bertelson CJ, Liechti-Gallati S, Moser H, Kunkel LM: An explanation for the phenotypic differences between patients bearing partial deletions of the DMD locus. Genomics 1988, 2:90-95.

2. Aartsma-Rus A, van Deutekom JC, Fokkema IF, van Ommen GJ, den Dunnen JT: Entries in the Leiden Duchenne muscular dystrophy mutation database: an overview of mutation types and paradoxical cases that confirm the reading-frame rule. Muscle Nerve 2006, 34:135-144.

3. Manzur AY, Muntoni F: Diagnosis and new treatments in muscular dystrophies. J Neurol Neurosurg Psychiatry 2009, 80:706-714.

4. Trollet C, Athanasopoulos T, Popplewell L, Malerba A, Dickson G: Gene therapy for muscular dystrophy: current progress and future prospects. Expert Opinion on Biological Therapy 2009, 9:849-866.

5. van Ommen GJ, van Deutekom JC, Aartsma-Rus A: The therapeutic potential of antisense-mediated exon skipping. Curr Opin Mol Ther 2008, 10:140-149.

6. Aartsma-Rus A, Bremmer-Bout M, Janson AA, den Dunnen JT, van Ommen GJ, van Deutekom JC: Targeted exon skipping as a potential gene correction therapy for Duchenne muscular dystrophy. Neuromuscul Disord 2002, 12(Suppl 1):S71-S77.

7. Aartsma-Rus A, Janson AA, Kaman WE, Bremmer-Bout M, den Dunnen JT, Baas F, van Ommen GJ, van Deutekom JC: Therapeutic antisense-induced exon skipping in cultured muscle cells from six different DMD patients. Hum Mol Genet 2003, 12:907-914.

8. Aartsma-Rus A, Janson AA, Kaman WE, Bremmer-Bout M, van Ommen GJ, den Dunnen JT, van Deutekom JC: Antisense-induced multiexon skipping for Duchenne muscular dystrophy makes more sense. Am J Hum Genet 2004, 74:83-92.

9. Mann CJ, Honeyman K, McClorey G, Fletcher S, Wilton SD: Improved antisense oligonucleotide induced exon skipping in the $\mathrm{mdx}$ mouse model of muscular dystrophy. J Gene Med 2002, 4:644-654.

10. Bremmer-Bout M, Aartsma-Rus A, de Meijer EJ, Kaman WE, Janson AA, Vossen $\mathrm{RH}$, van Ommen GJ, den Dunnen JT, van Deutekom JC: Targeted exon skipping in transgenic hDMD mice: A model for direct preclinical screening of human-specific antisense oligonucleotides. Mol Ther 2004, 10:232-240.

11. Heemskerk HA, de Winter $C L$, de Kimpe SJ, van Kuik-Romeijn P, Heuvelmans N, Platenburg GJ, van Ommen GJ, van Deutekom JC, AartsmaRus A: In vivo comparison of 2'-O-methyl phosphorothioate and morpholino antisense oligonucleotides for Duchenne muscular dystrophy exon skipping. J Gene Med 2009, 11:257-266.

12. van Deutekom JC, Janson AA, Ginjaar IB, Frankhuizen WS, Aartsma-Rus A, Bremmer-Bout M, den Dunnen JT, Koop K, van der Kooi AJ, Goemans NM, de Kimpe SJ, Ekhart PF, Venneker EH, Platenburg GJ, Verschuuren JJ, van Ommen GJ: Local Dystrophin Restoration with Antisense Oligonucleotide PRO051. N Engl J Med 2007, 357:2677-2686.

13. Kinali M, rechavala-Gomeza V, Feng L, Cirak S, Hunt D, Adkin C, Guglieri M, Ashton E, Abbs S, Nihoyannopoulos P, Garralda ME, Rutherford M, McCulley C, Popplewell L, Graham IR, Dickson G, Wood MJ, Wells DJ, Wilton SD, Kole R, Straub V, Bushby K, Sewry C, Morgan JE, Muntoni F: Local restoration of dystrophin expression with the morpholino oligomer AVI4658 in Duchenne muscular dystrophy: a single-blind, placebo-controlled, dose-escalation, proof-of-concept study. Lancet Neurol 2009, 8:918-928.

14. Yoshida N, Yoshida S, Koishi K, Masuda K, Nabeshima Y: Cell heterogeneity upon myogenic differentiation: down-regulation of MyoD and Myf-5 generates 'reserve cells'. J Cell Sci 1998, 111:769-779.

15. Hawke TJ, Garry DJ: Myogenic satellite cells: physiology to molecular biology. J Appl Physiol 2001, 91:534-551.

16. Blau HM, Webster C, Pavlath GK, Chiu CP: Evidence for defective myoblasts in Duchenne muscular dystrophy. Adv Exp Med Biol 1985, 182:85-110.

17. Clop A, Marcq F, Takeda H, Pirottin D, Tordoir X, Bibe B, Bouix J, Caiment F, Elsen JM, Eychenne F, Larzul C, Laville E, Meish F, Milenkovic D, Tobin J, Charlier C, Georges M: A mutation creating a potential illegitimate microRNA target site in the myostatin gene affects muscularity in sheep. Nat Genet 2006, 38:813-818.

18. McPherron AC, Lawler AM, Lee SJ: Regulation of skeletal muscle mass in mice by a new TGF-beta superfamily member. Nature 1997, 387:83-90.

19. McPherron $A C$, Lee $S J$ : Double muscling in cattle due to mutations in the myostatin gene. Proc Natl Acad Sci USA 1997, 94:12457-12461.

20. Schuelke M, Wagner KR, Stolz LE, Hubner C, Riebel T, Komen W, Braun T, Tobin JF, Lee SJ: Myostatin mutation associated with gross muscle hypertrophy in a child. N Engl J Med 2004, 350:2682-2688.

21. Shelton GD, Engvall E: Gross muscle hypertrophy in whippet dogs is caused by a mutation in the myostatin gene. Neuromuscul Disord 2007, 17:721-722.

22. Rebbapragada A, Benchabane $H$, Wrana JL, Celeste AJ, Attisano L: Myostatin signals through a transforming growth factor beta-like signaling pathway to block adipogenesis. Mol Cell Biol 2003, 23:7230-7242.

23. Langley B, Thomas M, Bishop A, Sharma M, Gilmour S, Kambadur R: Myostatin inhibits myoblast differentiation by down-regulating MyoD expression. J Biol Chem 2002, 277:49831-49840.

24. McFarlane C, Hennebry A, Thomas M, Plummer E, Ling N, Sharma M, Kambadur R: Myostatin signals through Pax7 to regulate satellite cell self-renewal. Experimental Cell Research 2008, 314:317-329.

25. Rios R, Carneiro I, Arce VM, Devesa J: Myostatin Regulates Cell Survival during C2C12 Myogenesis. Biochemical and Biophysical Research Communications 2001, 280:561-566.

26. Taylor WE, Bhasin S, Artaza J, Byhower F, Azam M, Willard DH Jr, Kull FC Jr, Gonzalez-Cadavid N: Myostatin inhibits cell proliferation and protein synthesis in C2C12 muscle cells. Am J Physiol Endocrinol Metab 2001, 280 E221-E228

27. Thomas M, Langley B, Berry C, Sharma M, Kirk S, Bass J, Kambadur R: Myostatin, a negative regulator of muscle growth, functions by inhibiting myoblast proliferation. J Biol Chem 2000, 275:40235-40243.

28. Bogdanovich S, Krag TO, Barton ER, Morris LD, Whittemore LA, Ahima RS, Khurana TS: Functional improvement of dystrophic muscle by myostatin blockade. Nature 2002, 420:418-421.

29. Krivickas $L S$, Walsh $R$, Amato AA: Single muscle fiber contractile properties in adults with muscular dystrophy treated with MYO-029. Muscle Nerve 2009, 39:3-9.

30. Wagner KR, Fleckenstein JL, Amato AA, Barohn RJ, Bushby K, Escolar DM, Flanigan KM, Pestronk A, Tawil R, Wolfe Gl, Eagle M, Florence JM, King WM, Pandya S, Straub V, Juneau P, Meyers K, Csimma C, Araujo T, Allen R, Parsons SA, Wozney JM, Lavallie ER, Mendell JR: A phase I/IItrial of MYO029 in adult subjects with muscular dystrophy. Ann Neurol 2008, 63:561-571.

31. Bogdanovich S, Perkins KJ, Krag TO, Whittemore LA, Khurana TS: Myostatin propeptide-mediated amelioration of dystrophic pathophysiology. FASEB J 2005, 19:543-549. 
32. Matsakas A, Foster K, Otto A, Macharia R, Elashry MI, Feist S, Graham I, Foster H, Yaworsky P, Walsh F, Dickson G, Patel K: Molecular, cellular and physiological investigation of myostatin propeptide-mediated muscle growth in adult mice. Neuromuscul Disord 2009, 19:489-499.

33. Qiao C, Li J, Jiang J, Zhu X, Wang B, Li J, Xiao X: Myostatin propeptide gene delivery by adeno-associated virus serotype 8 vectors enhances muscle growth and ameliorates dystrophic phenotypes in $\mathrm{mdx}$ mice. Hum Gene Ther 2008, 19:241-254.

34. Zhao B, Li EJ, Wall RJ, Yang J: Coordinated patterns of gene expression for adult muscle build-up in transgenic mice expressing myostatin propeptide. BMC Genomics 2009, 10:305.

35. Lee SJ, Reed LA, Davies MV, Girgenrath S, Goad ME, Tomkinson KN, Wright JF, Barker C, Ehrmantraut G, Holmstrom J, Trowell B, Gertz B, Jiang MS, Sebald SM, Matzuk M, Li E, Liang LF, Quattlebaum E, Stotish RL, Wolfman NM: Regulation of muscle growth by multiple ligands signaling through activin type II receptors. Proc Natl Acad Sci USA 2005, 102:18117-18122.

36. Li ZB, Kollias HD, Wagner KR: Myostatin directly regulates skeletal muscle fibrosis. J Biol Chem 2008, 283:19371-19378.

37. Dumonceaux J, Marie S, Beley C, Trollet C, Vignaud A, Ferry A, ButlerBrowne G, Garcia L: Combination of Myostatin Pathway Interference and Dystrophin Rescue Enhances Tetanic and Specific Force in Dystrophic mdx Mice. Mol Ther 2010.

38. Tang Y, Cummins J, Huard J, Wang B: AAV-directed muscular dystrophy gene therapy. Expert Opin Biol Ther 2010, 10:395-408.

39. Le RF, Charton $\mathrm{K}$, Lorson CL, Richard I: RNA-targeting approaches for neuromuscular diseases. Trends Mol Med 2009, 15:580-591.

40. Liu CM, Yang Z, Liu CW, Wang R, Tien P, Dale R, Sun LQ: Myostatin antisense RNA-mediated muscle growth in normal and cancer cachexia mice. Gene Ther 2008, 15:155-160.

41. Magee TR, Artaza JN, Ferrini MG, Vernet D, Zuniga Fl, Cantini L, ReiszPorszasz S, Rajfer J, Gonzalez-Cadavid NF: Myostatin short interfering hairpin RNA gene transfer increases skeletal muscle mass. J Gene Med 2006, 8:1171-1181.

42. Aartsma-Rus A, Janson AA, Kaman WE, Bremmer-Bout M, den Dunnen JT, Baas F, van Ommen GJ, van Deutekom JC: Therapeutic antisense-induced exon skipping in cultured muscle cells from six different DMD patients. Hum Mol Genet 2003, 12:907-914.

43. Zhu CH, Mouly V, Cooper RN, Mamchaoui K, Bigot A, Shay JW, Di Santo JP, Butler-Browne GS, Wright WE: Cellular senescence in human myoblasts is overcome by human telomerase reverse transcriptase and cyclindependent kinase 4: consequences in aging muscle and therapeutic strategies for muscular dystrophies. aging cell 2007, 6:515-523.

44. Aartsma-Rus A, van Vliet L, Hirschi M, Janson AA, Heemskerk H, de Winter $\mathrm{CL}$, de Kimpe S, van Deutekom JC, 't Hoen PA, van Ommen GJ: Guidelines for antisense oligonucleotide design and insight into splicemodulating mechanisms. Mol Ther 2009, 17:548-553.

45. Amthor H, Otto A, Macharia R, McKinnell I, Patel K: Myostatin imposes reversible quiescence on embryonic muscle precursors. Dev Dyn 2006, 235:672-680.

46. McCroskery S, Thomas M, Maxwell L, Sharma M, Kambadur R: Myostatin negatively regulates satellite cell activation and self-renewal. J Cell Biol 2003, 162:1135-1147.

47. Aartsma-Rus $\mathrm{A}$, de Winter $\mathrm{CL}$, Janson $\mathrm{AA}$, Kaman $\mathrm{WE}$, van Ommen $\mathrm{GJ}$, den Dunnen JT, van Deutekom JC: Functional analysis of 114 exon-internal AONs for targeted DMD exon skipping: indication for steric hindrance of SR protein binding sites. Oligonucleotides 2005, 15:284-297.

48. Mathews DH, Turner DH, Zuker M: RNA secondary structure prediction. Curr Protoc Nucleic Acid Chem 2007, Chapter 11(Unit 11.2).

49. Kang JK, Malerba A, Popplewell L, Foster K, Dickson G: Antisense-induced Myostatin Exon Skipping Leads to Muscle Hypertrophy in Mice Following Octa guanidine Morpholino Oligomer Treatment. Mol Ther 2010.

50. Lee SJ: Quadrupling Muscle Mass in Mice by Targeting TGF- $\beta$ Signaling Pathways. PLOS ONE 2007, 2:e789.

51. Souza TA, Chen X, Guo Y, Sava P, Zhang J, Hill JJ, Yaworsky PJ, Qiu Y: Proteomic identification and functional validation of activins and bone morphogenetic protein 11 as candidate novel muscle mass regulators. Mol Endocrinol 2008, 22:2689-2702.

\section{Pre-publication history}

The pre-publication history for this paper can be accessed here: http://www.biomedcentral.com/1755-8794/4/36/prepub

doi:10.1186/1755-8794-4-36

Cite this article as: Kemaladewi et al:: Dual exon skipping in myostatin and dystrophin for Duchenne muscular dystrophy. BMC Medical

Genomics 2011 4:36.

\section{Submit your next manuscript to BioMed Central and take full advantage of:}

- Convenient online submission

- Thorough peer review

- No space constraints or color figure charges

- Immediate publication on acceptance

- Inclusion in PubMed, CAS, Scopus and Google Scholar

- Research which is freely available for redistribution

Submit your manuscript at www.biomedcentral.com/submit
Biomed Central 